\title{
Miniaturized String Sampling Probe and Electrospray Extraction/lonization within the Ion Inlet Tube for Mass Spectrometric Endoscopy
}

Lee Chuin Chen ${ }^{1 *}$, Tomohiko Iwano ${ }^{2}$, Satoshi Ninomiya ${ }^{1}$, Takayuki Koike ${ }^{3}$, Yoshihisa Tanaka ${ }^{3}$, Kentaro Yoshimura $^{2 *}$

${ }^{1}$ Faculty of Engineering, University of Yamanashi, 4-3-11, Takeda, Kofu, Yamanashi, 400-8511 Japan

${ }^{2}$ Department of Anatomy and Cell Biology, Faculty of Medicine, University of Yamanashi, 1110, Shimokato, Chuo, Yamanashi, 409-3898 Japan

${ }^{3}$ ARS Corp. 3201-1, Ubaguchi, Kofu, Yamanashi, 400-1504 Japan

*To whom correspondence should be addressed:

L. C. Chen, E-mail: leechuin@yamanashi.ac.jp, Phone: +81-55-220-8072

K. Yoshimura, E-mail: kyoshimura@yamanashi.ac.jp, Phone: +81-55-273-9475

\section{Contents}

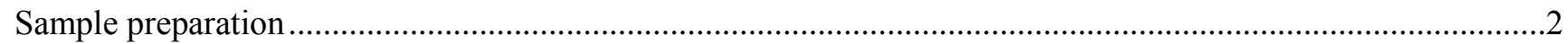

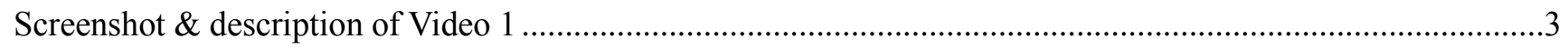

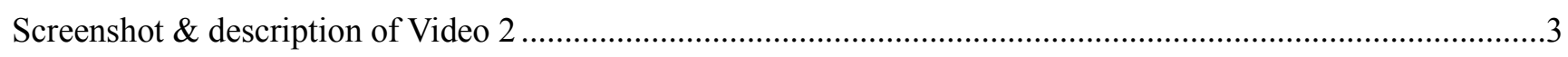

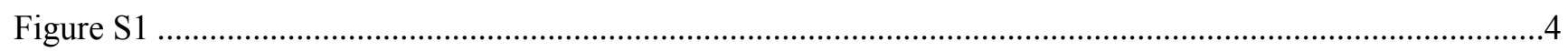

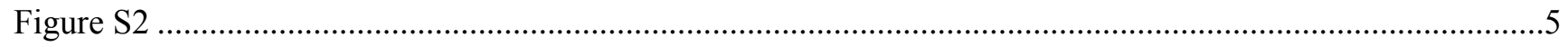

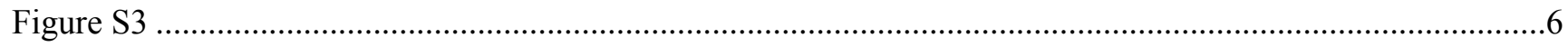

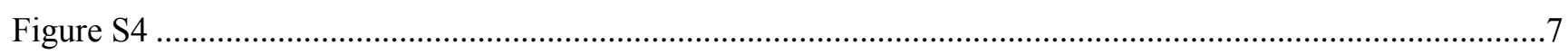

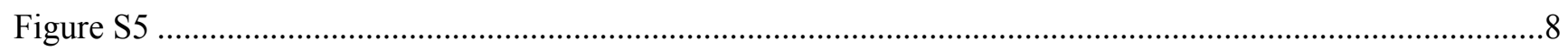

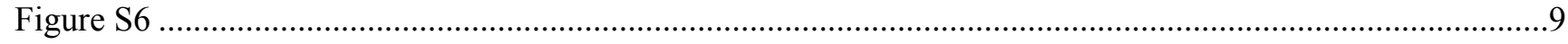

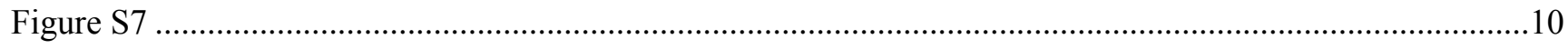

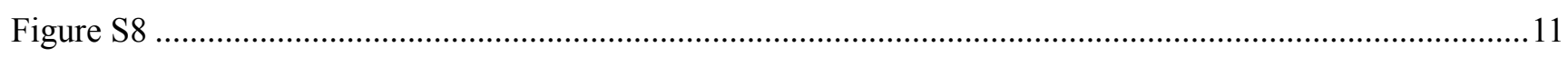

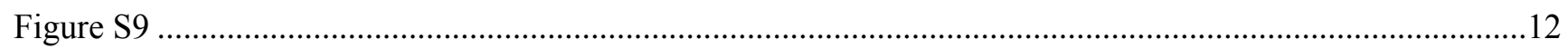

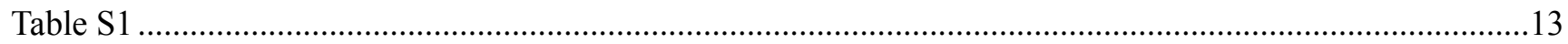




\section{Sample preparation}

For the tuning of the ion source, L- $\alpha$-phosphatidylcholine, dioleoyl, (Fuji Wako, Osaka, Japan) was prepared in methanol solution $(5 \mu \mathrm{M})$ and an aliquot of $0.1 \mu \mathrm{L}$ was deposited onto the sampling string. The mouse used in the in-vivo experiment was anesthetized by intraperitoneal injection using $0.1 \mathrm{ml} / 10 \mathrm{~g}$ body weight of $30 \mu \mathrm{g} / \mathrm{mL}$ medetomidine (Dorbene, Kyoritsu Seiyaku, Tokyo, Japan), $0.4 \mathrm{mg} / \mathrm{mL}$ midazolam (Sandoz, Tokyo, Japan), and $0.5 \mathrm{mg} / \mathrm{mL}$ butorphanol tartrate (Vetorphale, Meiji Seika Pharma, Tokyo, Japan) in sterilized saline (Otsuka Pharmaceutical, Tokyo, Japan). After the anesthesia, the abdominal skin, peritoneum, and the greater curvature of the stomach were incised to exposure to the lumen of the stomach. The surface of gastric mucosa was washed by deionized water and gently wiped to remove the food contents of the stomach. The whole experiment finished within $60 \mathrm{~min}$. The procedures were approved by the ethics committee of the University of Yamanashi (No. A27$10)$.

\section{Tissue staining}

In a separate experiment, the stomach of the mouse was removed from the body after the sampling process using string. The tissue was washed briefly in PBS and fixed by immersion in 10\% formalin neutral-buffered solution (Muto pure chemicals, Tokyo, Japan) for 24 hours at room temperature. The tissue was transferred to the $10 \%$ sucrose in PBS for 4 hours and then 30\% sucrose in PBS for 24 hours for cryopreservation. Tissue was embedded in the O. C. T. compound (Sakura Finetek, Tokyo, Japan) and frozen by liquid nitrogen. The frozen block of the stomach was sectioned in 5- $\mu \mathrm{m}$ thickness by using Cryostat CM 1520 (Leica Microsystems, Wetzlar, Germany). Cryosections were placed on MAS-coated glass slides (MAS-GP, Matsunami Glass Ind., Osaka, Japan) and dried up for $30 \mathrm{~min}$ at room temperature. Slides were stained using Hematoxylin and Eosin (H\&E) stain kit (Scy Tek Laboratories, UT) following the manufacturer's instruction. Images of stained sections were obtained using an inverted microscope (IX71, Olympus, Tokyo, Japan). 


\section{Screenshot \& description of Video 1}

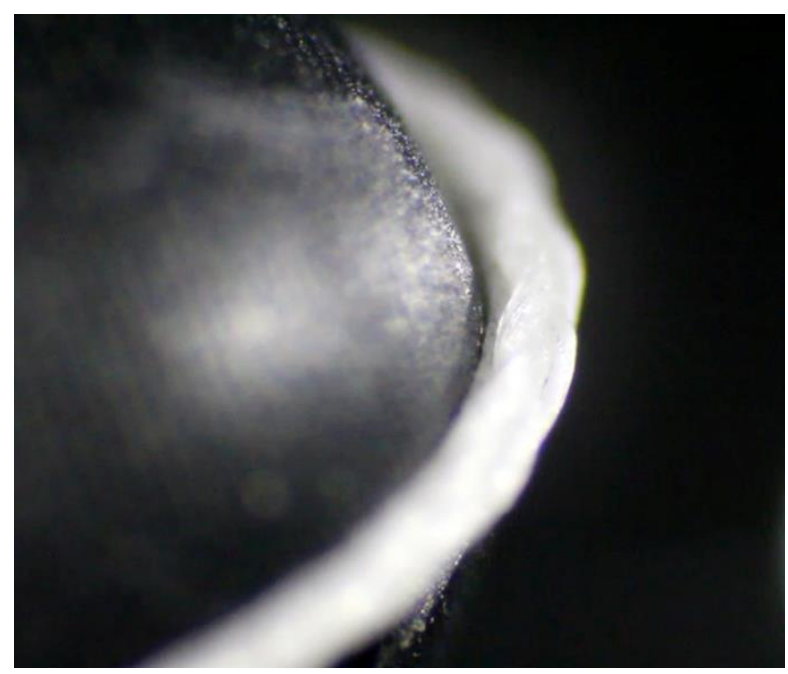

Movement of the sampling string at the probe head inspected using an optical microscope.

\section{Screenshot \& description of Video 2}

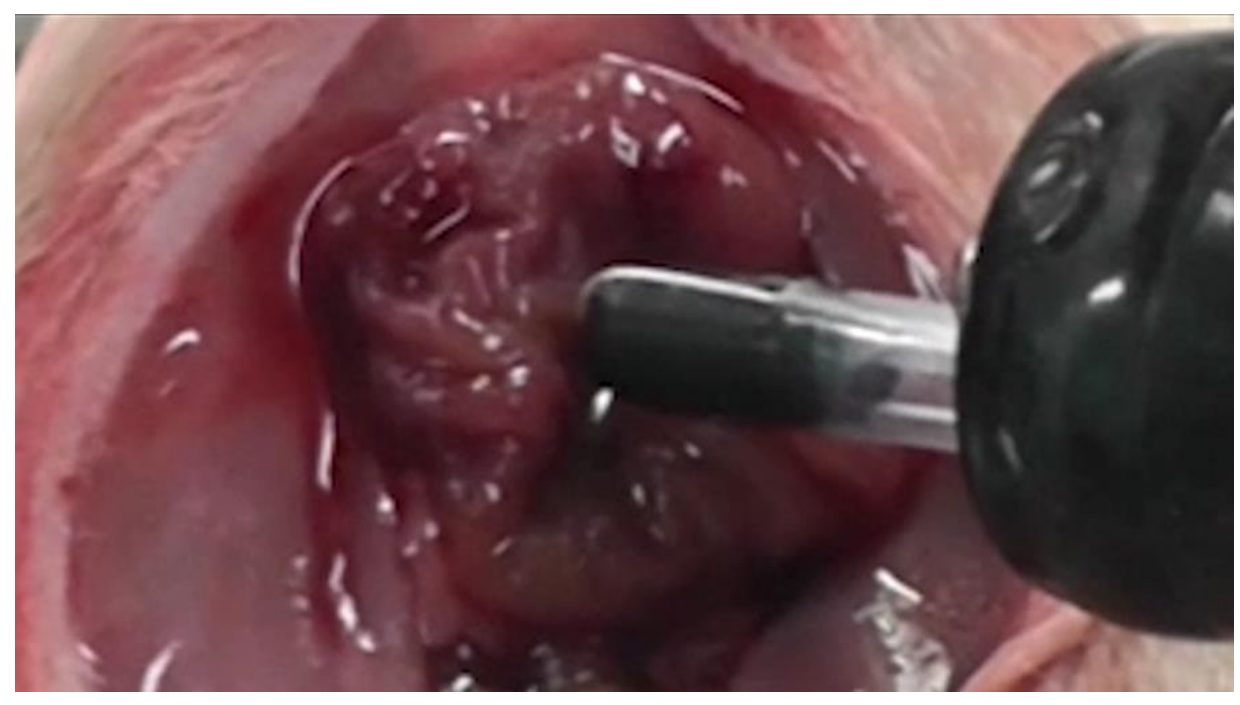

Procedure of performing the in vivo MS acquisition on the gastric mucosa of a living mouse using the string sampling probe incorporated into an endoscope. 


\section{Figure S1}

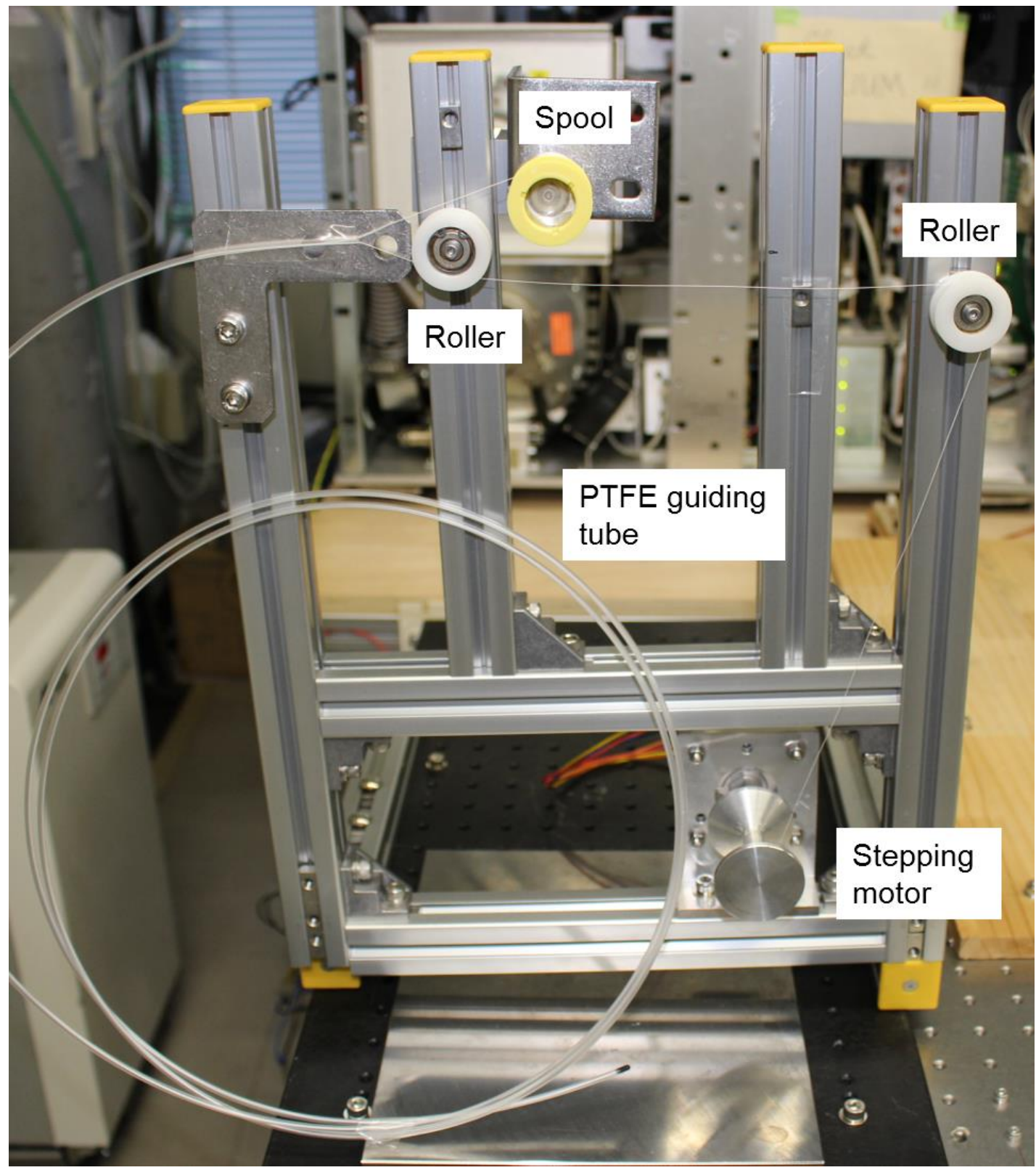

Photograph showing the drawing of the sampling string (silk suture) using a stepping motor and a set of rollers.

The length of the PTFE guiding tube is $2.5 \mathrm{~m}$. A single strand fishing line (nylon) is used to assist the insertion of the silk suture to the $2.5 \mathrm{~m}$ long PTFE tube. 
Figure S2

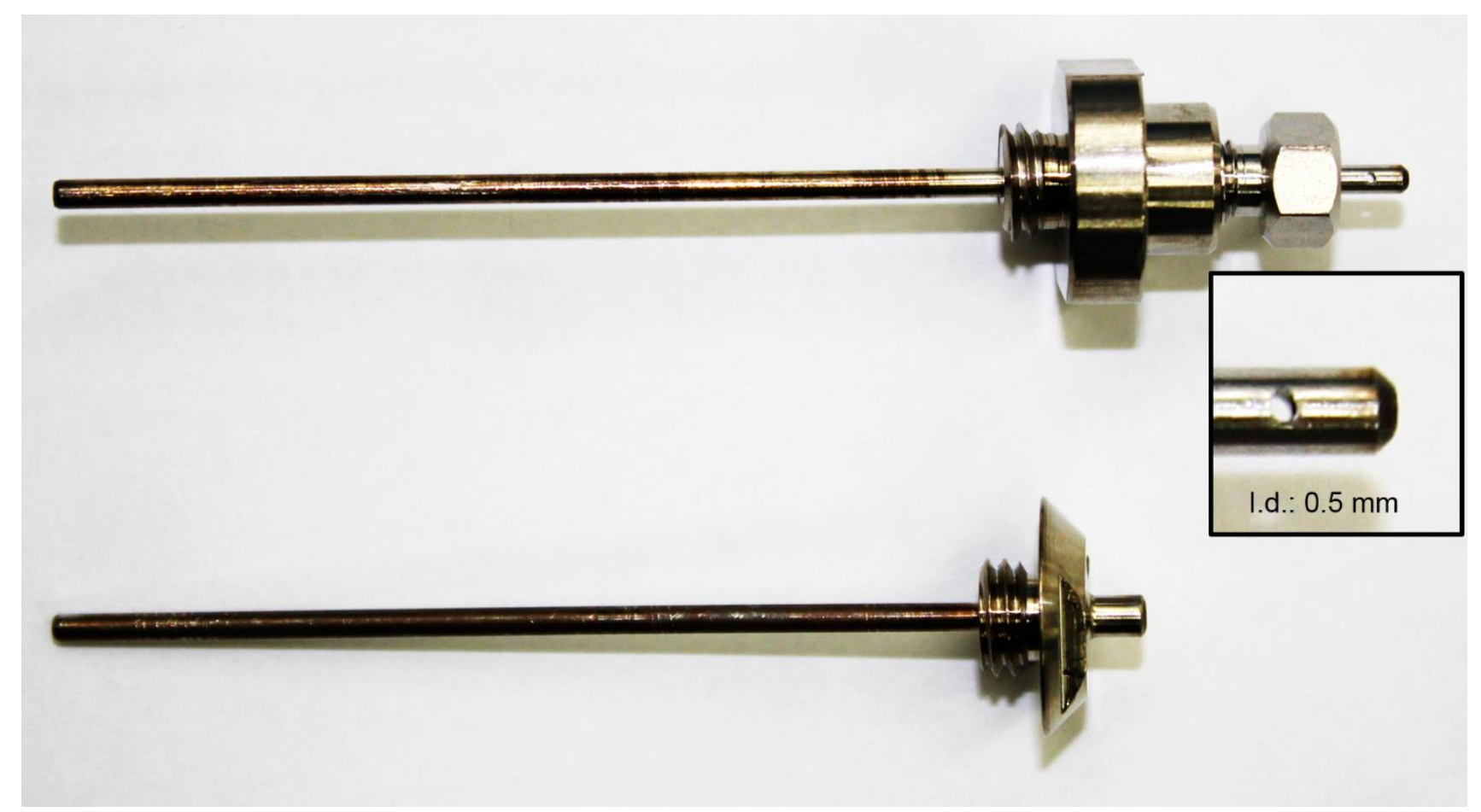

Upper: Custom-made ion inlet tube with i.d. of $0.5 \mathrm{~mm}$. Inset shows the magnification near the ion inlet entrance.

Two side holes are made for the guiding of the sampling string to move across the inner channel of the ion inlet tube. Lower: Original ion inlet tube for LTQ-Velos (Thermo Fisher Scientific). 
Figure $\mathbf{S 3}$
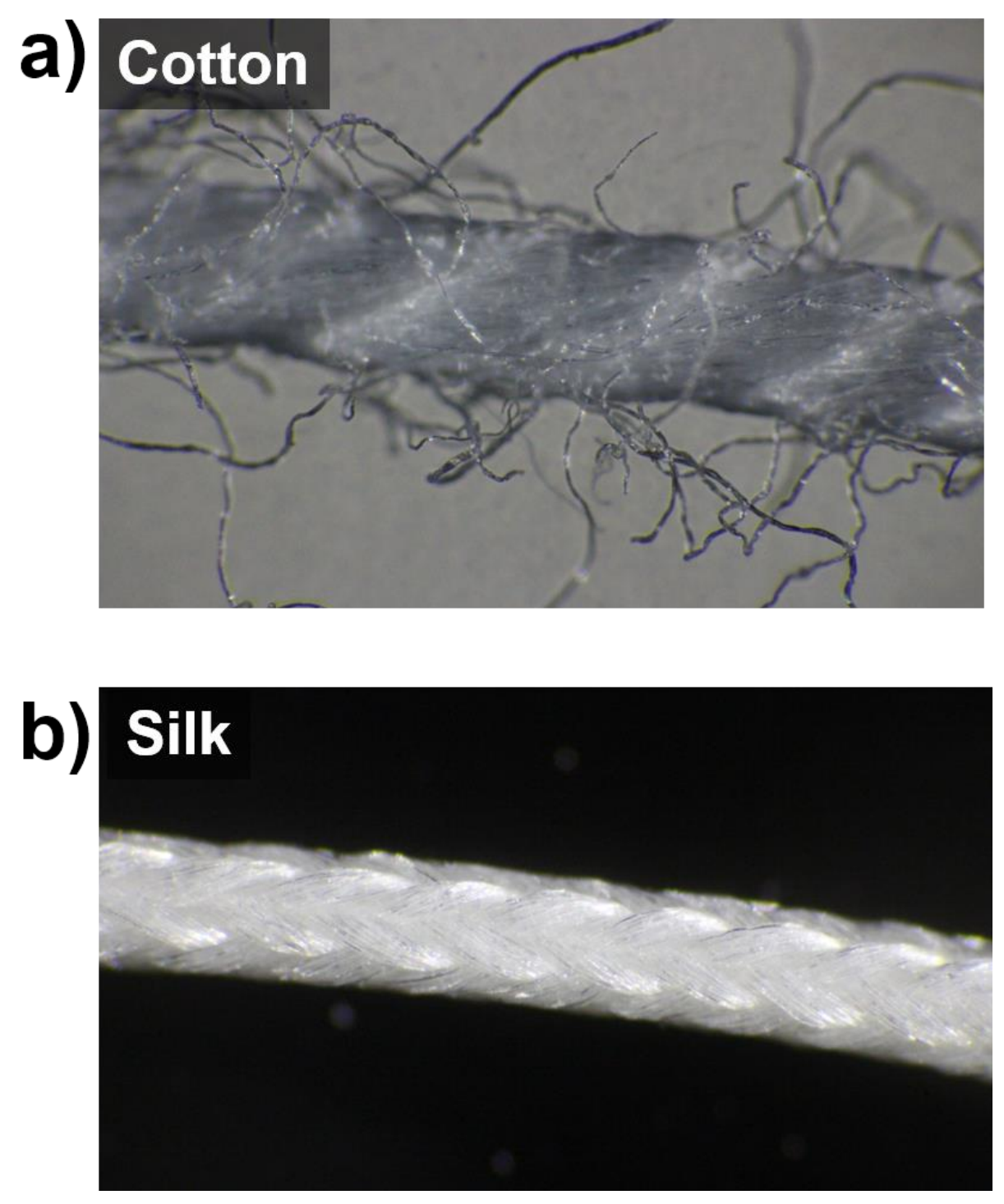

Microscopic inspections of the tested sampling string. a) Cotton thread. b) Silk suture. The diameter of the silk suture is approximately $0.2 \mathrm{~mm}$. 
Figure S4
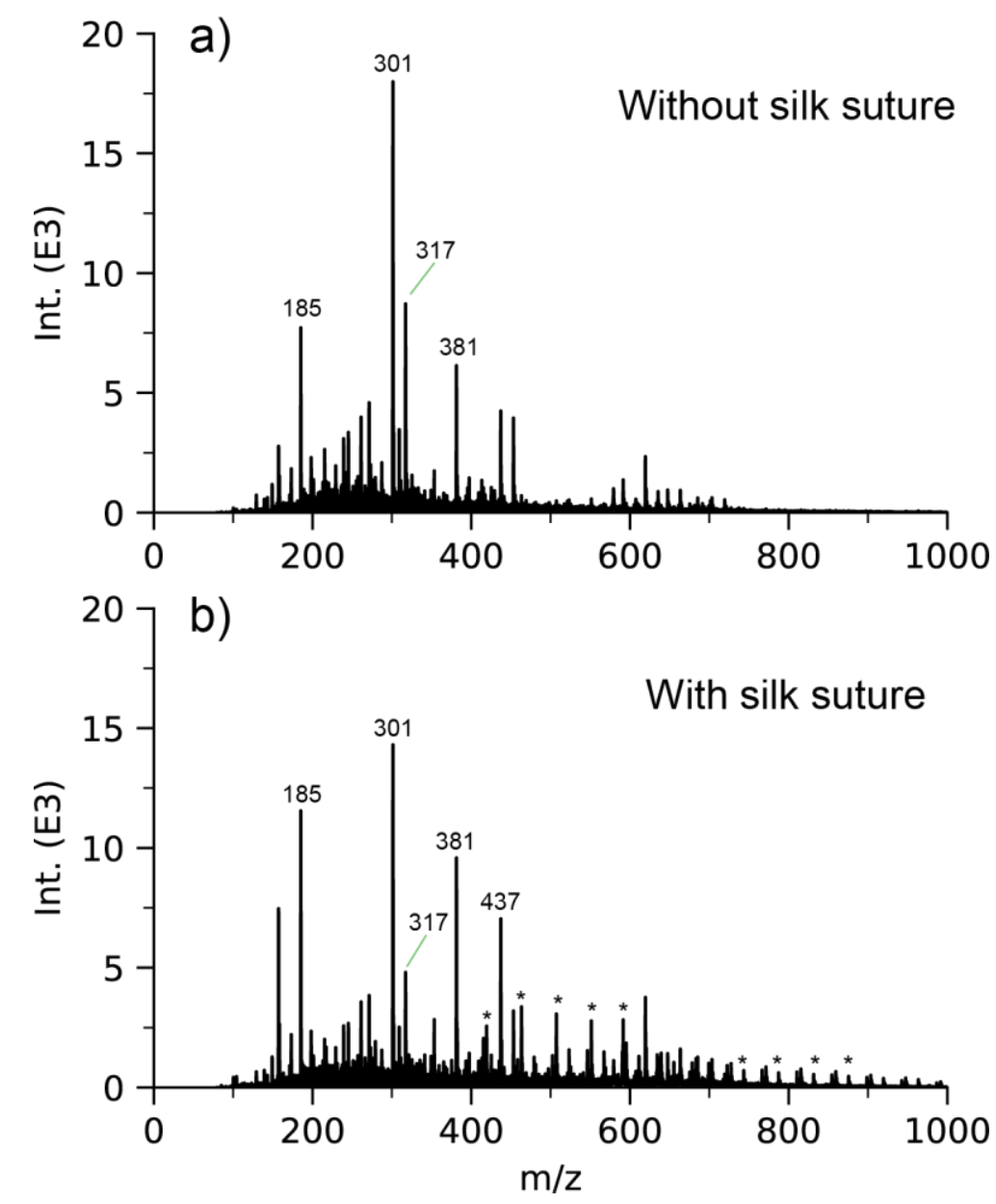

a) Mass spectrum of the $50 \% \mathrm{v} / \mathrm{v}$ ethanol solvent without the insertion of silk suture into the ion inlet tube. b) Mass spectrum acquired after the insertion of the silk suture into the ion inlet tube. The major peaks at $m / z 301$ for both mass spectra are due to the sodiated dibutylphalate $\left(\left[\mathrm{C}_{16} \mathrm{H}_{22} \mathrm{O}_{4}+\mathrm{Na}^{+}\right]\right.$, theoretical monoisotopic mass $=$ 301.1410). The measured $\mathrm{m} / \mathrm{z}$ of this peak using Exactive Orbitrap is 301.1411. Asterisks indicate a distribution of peaks with $44.02 \mathrm{u}$ spacing, originating from the polyethylene glycol (PEG) related ions. 


\section{Figure S5}

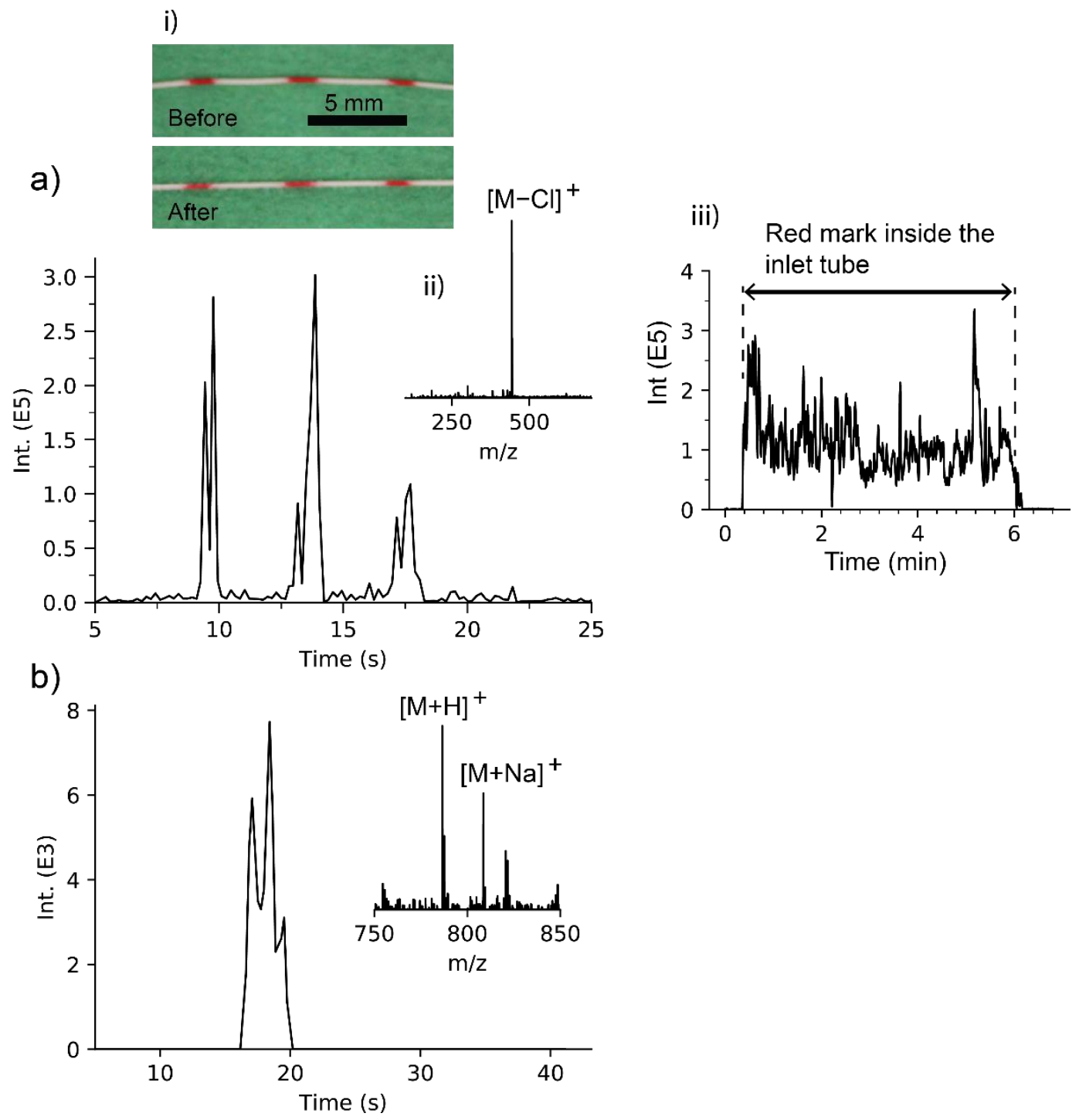

a) EIC of $[\mathrm{M}-\mathrm{Cl}]^{+}$showing the detection of Rhodamine $\mathrm{B}$ and/or $6 \mathrm{G}$ from the red ink marked on the sampling string using an oil-based marker pen (Pilot). String drawing speed: $\sim 1 \mathrm{~mm} / \mathrm{s}$. Insets (i) \& (ii): Photographs showing the position of the marks and the mass spectrum. The sharp rise and drop of the Rhodamine cation signal indicate a good spatial resolution for the ion source to resolve the sample distribution on the string. With a $50 \%$ $\mathrm{v} / \mathrm{v}$ ethanol solution, the dispersion of ink was not observed after 8 repeated measurements (inset ii). Inset iii) shows the EIC of another measurement by stopping the string movement when the red mark is inside the inlet tube. The $[\mathrm{M}-\mathrm{Cl}]^{+}$signal dropped to baseline level in less than $10 \mathrm{~s}$ when the mark is drawn out of the inlet tube after 6 min.

b) Detection of $500 \mathrm{fmol}$ L- $\alpha$-phosphatidylcholine, dioleoyl (PC 18:1/18:1) deposited on the silk suture using the present ion source. An aliquot of $0.1 \mu \mathrm{L}$ sample solution was deposited using a precision micropipette and the sample spreads on a spot of approximately $\sim 1 \mathrm{~mm}$ in length. The ion chromatogram depicts the sum of the signal from the protonated and sodiated species. The same sample of this amount cannot be detected using our previous ion source (ref. 12.). The detection limit of this lipid standard is approximately $100 \mathrm{fmol}$. 


\section{Figure S6}
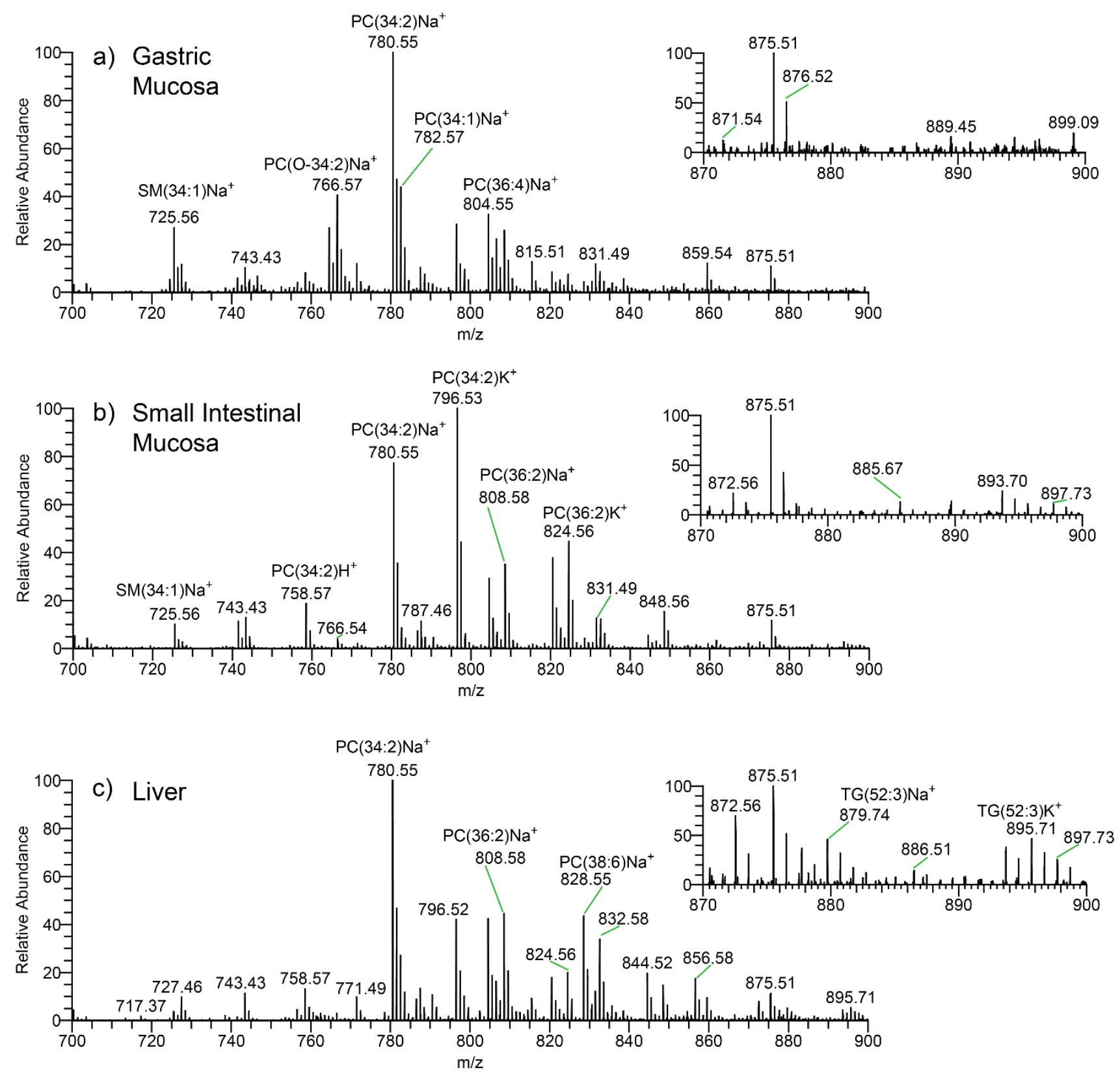

Positive mass spectra of a) gastric mucosa, b) small intestinal mucosa, and c) liver of mouse using the string sampling method and high-resolution mass spectrometer (Exactive Orbitrap, Thermo Fisher Scientific). Insets show the magnified mass spectra. Besides differences in the distribution of phosphatidylcholine (PC), ether phosphatidylcholine [e.g. $\mathrm{PC}(\mathrm{O}-34: 2)]$ and sphingomyelin $(\mathrm{SM})$ are detected with higher abundance from the gastric mucosa. The liver shows a trace of triacylglycerol (TG) not found in a) and b). The peak at $\mathrm{m} / \mathrm{z} 875.51$ is due to the PEG related background ion. 
Figure S7
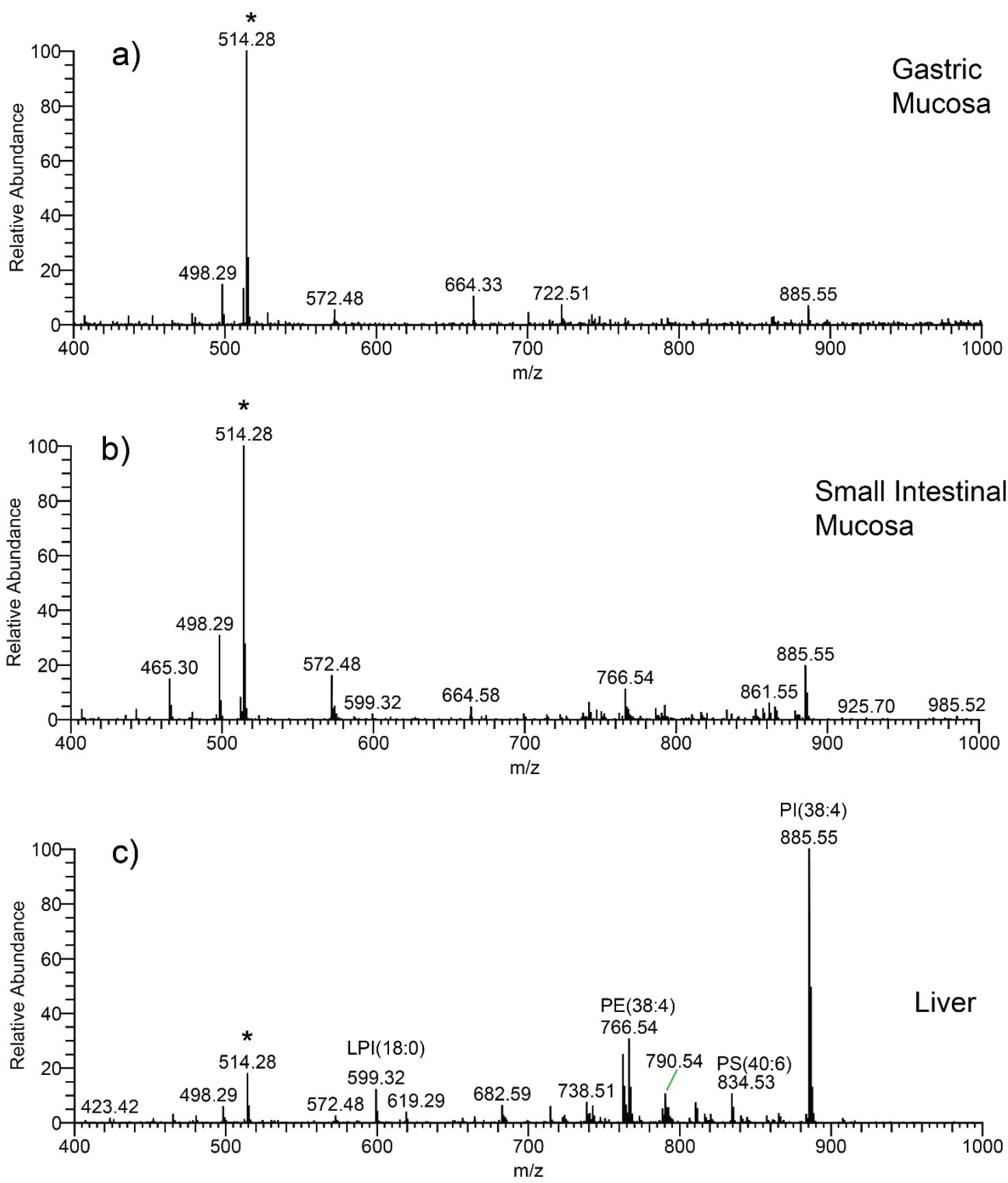

Negative mass spectra of a) gastric mucosa, b) small intestinal mucosa, and c) liver of mouse. * denote peak from taurocholate ion $\left(\mathrm{C}_{26} \mathrm{H}_{44} \mathrm{NO}_{7} \mathrm{~S}^{-}\right)$. 


\section{Figure S8}
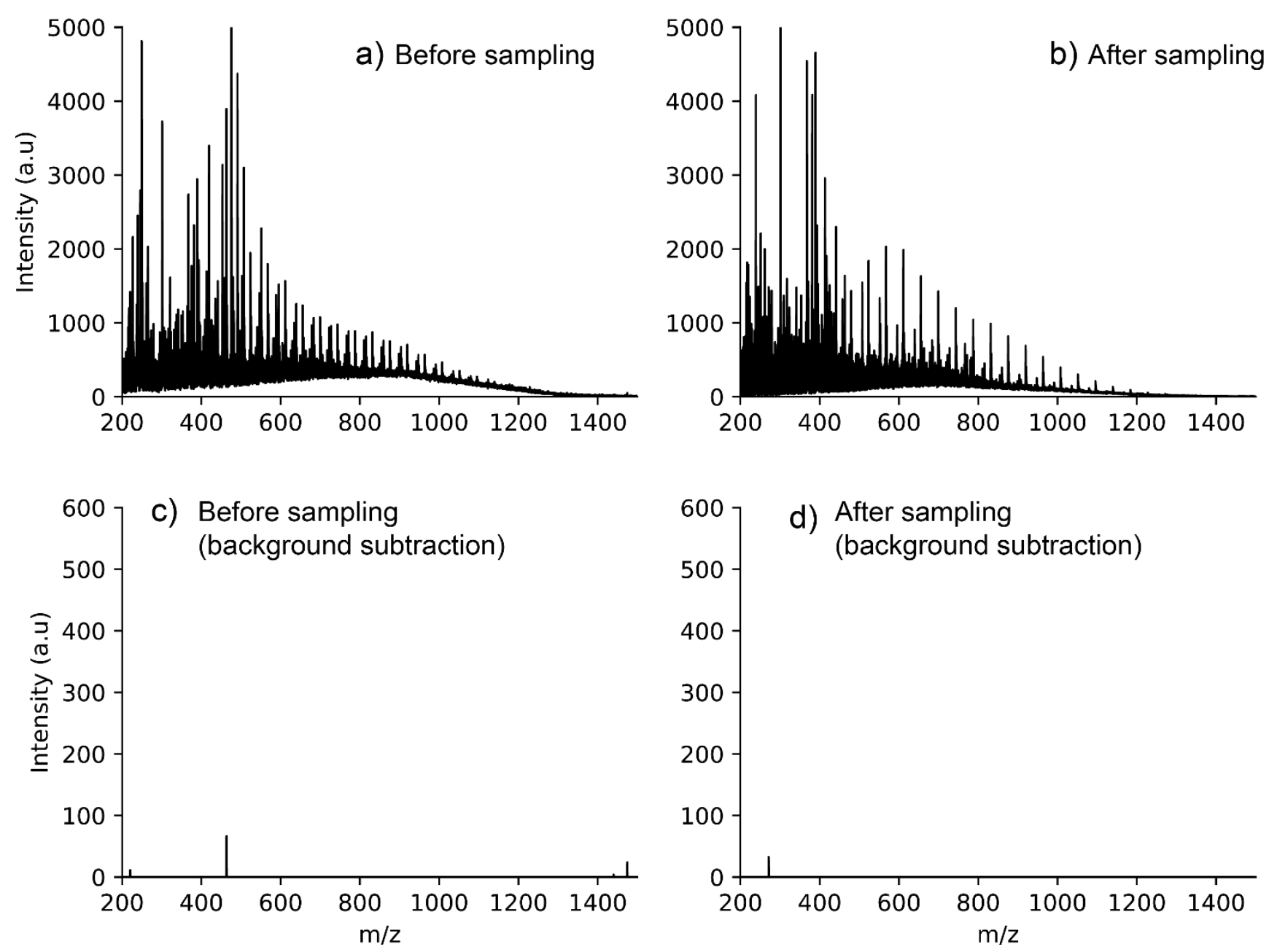

Mass spectra a) \& c) taken before the appearance of lipid peaks ( 2 to 2.7 min in Figure $3 b$ ), and b) \& d) taken after the disappearance of lipid peaks ( 7.5 to $8.5 \mathrm{~min}$ ). The mass spectrum taken during the first minute before moving the sampling string is used for background subtraction. 


\section{Figure S9}
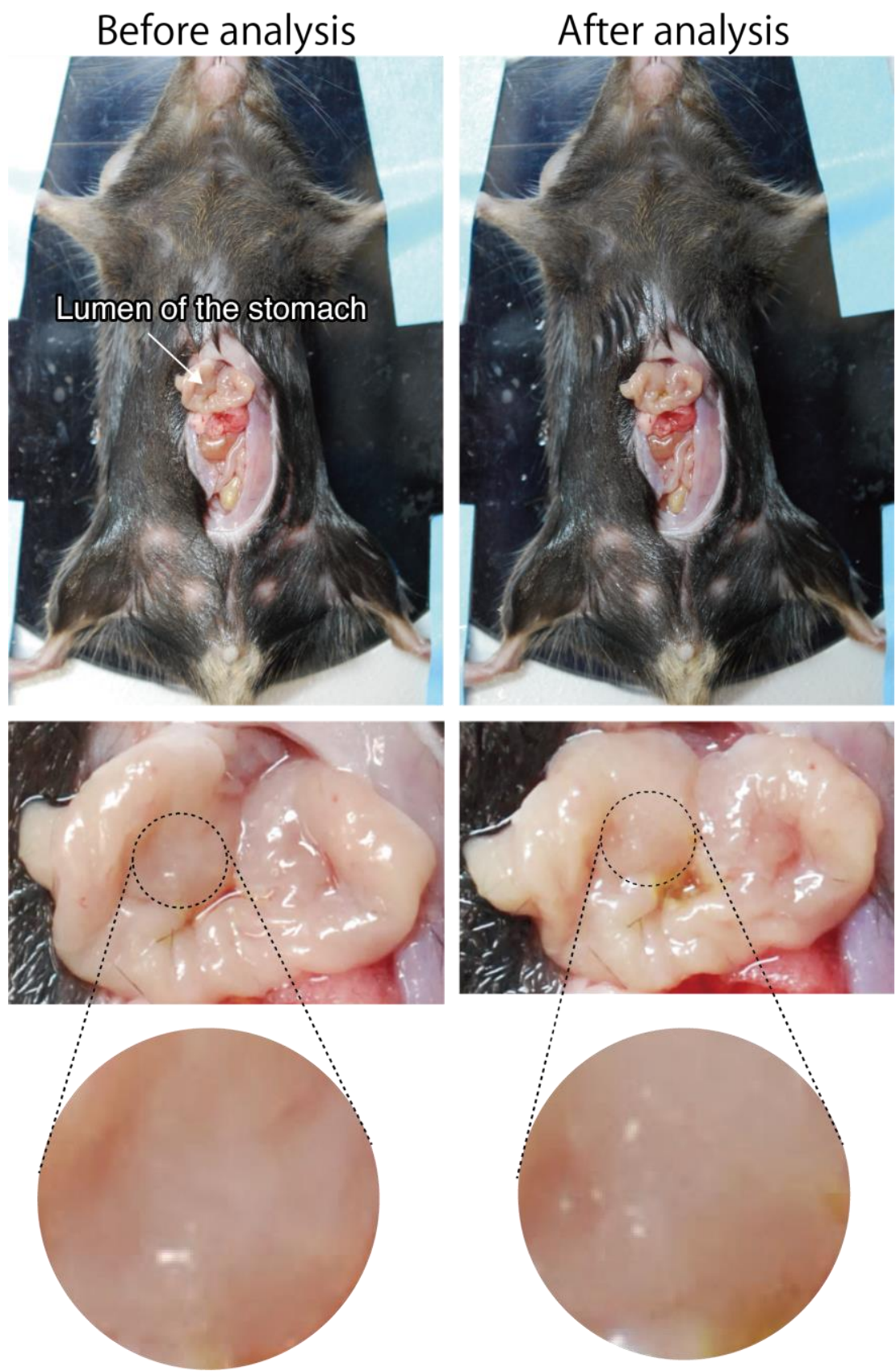

Photographs showing the lumen of the stomach and the sampling location (mucosal surface, dashed circle) taken before and after the analysis. The "wound" caused by the string sampling probe is not observable by the naked eye or using a digital camera. The diameter of the dashed circle is $\sim 4 \mathrm{~mm}$. The crater due to the removal of the gastric epithelium by the sampling string is observable under the microscope with H\&E staining (Figure 3d). 


\section{Table S1}

List of selected peaks and their intensities acquired from gastric mucosa, small intestinal mucosa, and liver of a mouse in the positive and negative ion modes.
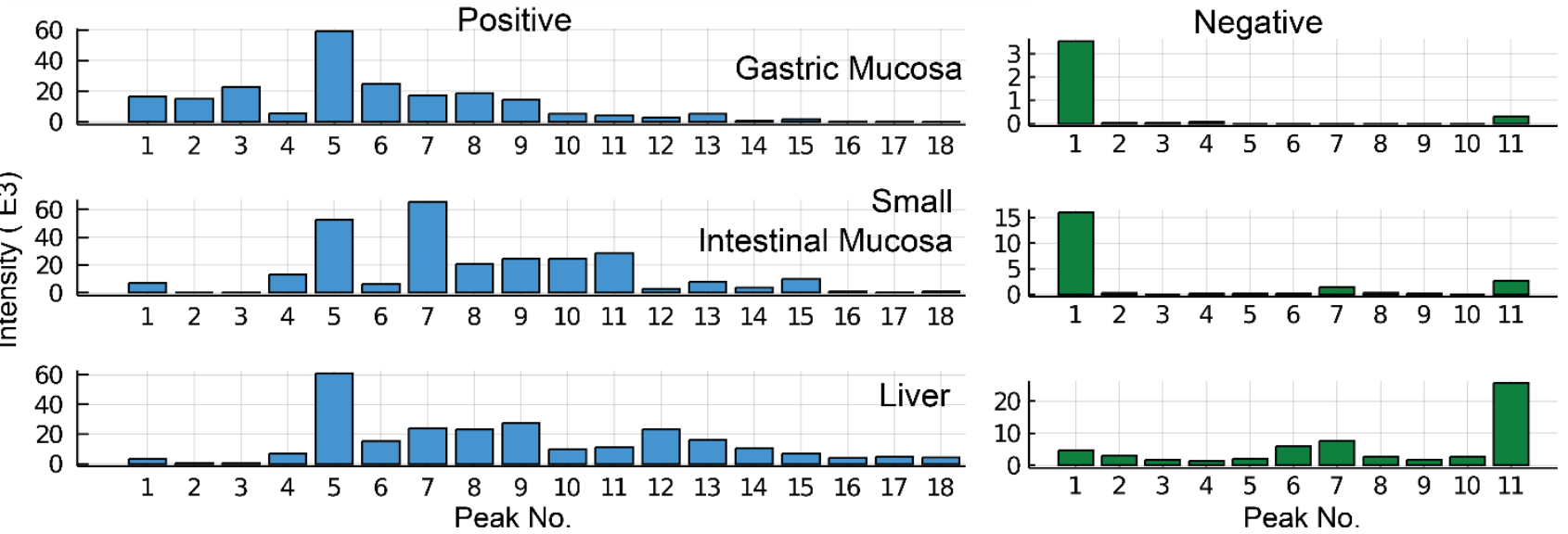

\begin{tabular}{|c|c|c|c|c|c|c|}
\hline $\begin{array}{l}\text { Peak } \\
\text { No. }\end{array}$ & $\begin{array}{c}\text { Measured } \\
m / z\end{array}$ & $\begin{array}{c}\text { Theoretical } \\
\text { monoisotopic } \\
\text { mass }\end{array}$ & Formula & Ion & Identity & Error (ppm) \\
\hline \multicolumn{7}{|c|}{ Positive ion mode } \\
\hline 1 & 725.5560 & 725.5568 & $\mathrm{C}_{39} \mathrm{H}_{79} \mathrm{~N}_{2} \mathrm{O}_{6} \mathrm{PNa}$ & {$[\mathrm{M}+\mathrm{Na}]+$} & SM(34:1) & 1.10 \\
\hline 2 & 764.5556 & 764.5565 & $\mathrm{C}_{42} \mathrm{H}_{80} \mathrm{NO}_{7} \mathrm{PNa}$ & {$[\mathrm{M}+\mathrm{Na}]+$} & $\mathrm{PC}(0-34: 3)$ & 1.18 \\
\hline 3 & 766.5714 & 766.5721 & $\mathrm{C}_{42} \mathrm{H}_{82} \mathrm{NO}_{7} \mathrm{PNa}$ & {$[\mathrm{M}+\mathrm{Na}]+$} & $\mathrm{PC}(\mathrm{O}-34: 2)$ & 0.91 \\
\hline 4 & 758.5685 & 758.5694 & $\mathrm{C}_{42} \mathrm{H}_{81} \mathrm{NO}_{8} \mathrm{P}$ & {$[\mathrm{M}+\mathrm{H}]+$} & $\mathrm{PC}(34: 2)$ & 1.19 \\
\hline 5 & 780.5505 & 780.5514 & $\mathrm{C}_{42} \mathrm{H}_{80} \mathrm{NO}_{8} \mathrm{PNa}$ & {$[\mathrm{M}+\mathrm{Na}]+$} & $\mathrm{PC}(34: 2)$ & 1.15 \\
\hline 6 & 782.5667 & 782.5670 & $\mathrm{C}_{42} \mathrm{H}_{82} \mathrm{NO}_{8} \mathrm{PNa}$ & {$[\mathrm{M}+\mathrm{Na}]+$} & $\mathrm{PC}(34: 1)$ & 0.38 \\
\hline 7 & 796.5244 & 796.5252 & $\mathrm{C}_{42} \mathrm{H}_{80} \mathrm{NO}_{8} \mathrm{PK}$ & {$[\mathrm{M}+\mathrm{K}]+$} & $\mathrm{PC}(34: 2)$ & 1.00 \\
\hline 8 & 804.5507 & 804.5514 & $\mathrm{C}_{44} \mathrm{H}_{80} \mathrm{NO}_{8} \mathrm{PNa}$ & {$[\mathrm{M}+\mathrm{Na}]+$} & $\mathrm{PC}(36: 4)$ & 0.87 \\
\hline 9 & 808.5821 & 808.5827 & $\mathrm{C}_{44} \mathrm{H}_{84} \mathrm{NO}_{8} \mathrm{PNa}$ & {$[\mathrm{M}+\mathrm{Na}]+$} & $\mathrm{PC}(36: 2)$ & 0.74 \\
\hline 10 & 820.5245 & 820.5253 & $\mathrm{C}_{44} \mathrm{H}_{80} \mathrm{NO}_{8} \mathrm{PK}$ & {$[\mathrm{M}+\mathrm{K}]+$} & $\mathrm{PC}(36: 4)$ & 0.97 \\
\hline 11 & 824.5559 & 824.5566 & $\mathrm{C}_{44} \mathrm{H}_{84} \mathrm{NO}_{8} \mathrm{PK}$ & {$[\mathrm{M}+\mathrm{K}]+$} & $\mathrm{PC}(36: 2)$ & 0.85 \\
\hline 12 & 828.5505 & 828.5514 & $\mathrm{C}_{46} \mathrm{H}_{80} \mathrm{NO}_{8} \mathrm{PNa}$ & {$[\mathrm{M}+\mathrm{Na}]+$} & $\mathrm{PC}(38: 6)$ & 1.09 \\
\hline 13 & 832.5821 & 832.5827 & $\mathrm{C}_{46} \mathrm{H}_{84} \mathrm{NO}_{8} \mathrm{PNa}$ & {$[\mathrm{M}+\mathrm{Na}]+$} & $\mathrm{PC}(38: 4)$ & 0.72 \\
\hline 14 & 844.5246 & 844.5253 & $\mathrm{C}_{46} \mathrm{H}_{80} \mathrm{NO}_{8} \mathrm{PK}$ & {$[\mathrm{M}+\mathrm{K}]+$} & $\mathrm{PC}(38: 6)$ & 0.83 \\
\hline 15 & 848.5562 & 848.5566 & $\mathrm{C}_{46} \mathrm{H}_{84} \mathrm{NO}_{8} \mathrm{PK}$ & {$[\mathrm{M}+\mathrm{K}]+$} & $\mathrm{PC}(38: 4)$ & 0.47 \\
\hline 16 & 877.7249 & 877.7256 & $\mathrm{C}_{55} \mathrm{H}_{98} \mathrm{O}_{6} \mathrm{Na}$ & {$[\mathrm{M}+\mathrm{Na}]+$} & $\mathrm{TG}(52: 4)$ & 0.80 \\
\hline 17 & 879.7406 & 879.7412 & $\mathrm{C}_{55} \mathrm{H}_{100} \mathrm{O}_{6} \mathrm{Na}$ & {$[\mathrm{M}+\mathrm{Na}]+$} & $\mathrm{TG}(52: 3)$ & 0.68 \\
\hline 18 & 895.7150 & 895.7151 & $\mathrm{C}_{55} \mathrm{H}_{100} \mathrm{O}_{6} \mathrm{~K}$ & {$[\mathrm{M}+\mathrm{K}]+$} & $\mathrm{TG}(52: 3)$ & 0.11 \\
\hline \multicolumn{7}{|c|}{ Negative ion mode } \\
\hline 1 & 514.2845 & 514.2838 & $\mathrm{C}_{26} \mathrm{H}_{44} \mathrm{NO}_{7} \mathrm{~S}$ & {$[\mathrm{M}-\mathrm{H}]-$} & Taurocholate & 1.36 \\
\hline 2 & 599.3206 & 599.3202 & $\mathrm{C}_{27} \mathrm{H}_{52} \mathrm{O}_{12} \mathrm{P}$ & {$[\mathrm{M}-\mathrm{H}]-$} & LPI(18:0) & 0.67 \\
\hline 3 & 682.5914 & 682.5911 & $\mathrm{C}_{42} \mathrm{H}_{81} \mathrm{NO}_{3} \mathrm{Cl}$ & {$[\mathrm{M}+\mathrm{Cl}]-$} & Cer(d18:1/24:1) & 0.44 \\
\hline 4 & 714.5086 & 714.5079 & $\mathrm{C}_{39} \mathrm{H}_{73} \mathrm{NO}_{8} \mathrm{P}$ & {$[\mathrm{M}-\mathrm{H}]-$} & $\mathrm{PE}(34: 2)$ & 0.98 \\
\hline 5 & 738.5085 & 738.5079 & $\mathrm{C}_{41} \mathrm{H}_{73} \mathrm{NO}_{8} \mathrm{P}$ & {$[\mathrm{M}-\mathrm{H}]-$} & $\operatorname{PE}(36: 4)$ & 0.81 \\
\hline 6 & 762.5084 & 762.5079 & $\mathrm{C}_{43} \mathrm{H}_{73} \mathrm{NO}_{8} \mathrm{P}$ & {$[\mathrm{M}-\mathrm{H}]-$} & $\mathrm{PE}(38: 6)$ & 0.66 \\
\hline 7 & 766.5398 & 766.5392 & $\mathrm{C}_{43} \mathrm{H}_{77} \mathrm{NO}_{8} \mathrm{P}$ & {$[\mathrm{M}-\mathrm{H}]-$} & $\operatorname{PE}(38: 4)$ & 0.78 \\
\hline 8 & 790.5399 & 790.5392 & $\mathrm{C}_{45} \mathrm{H}_{77} \mathrm{NO}_{8} \mathrm{P}$ & {$[\mathrm{M}-\mathrm{H}]-$} & $\mathrm{PE}(40: 6)$ & 0.89 \\
\hline 9 & 810.5298 & 810.5291 & $\mathrm{C}_{44} \mathrm{H}_{77} \mathrm{NO}_{10} \mathrm{P}$ & {$[\mathrm{M}-\mathrm{H}]-$} & $\mathrm{PS}(38: 4)$ & 0.86 \\
\hline 10 & 834.5299 & 834.5291 & $\mathrm{C}_{46} \mathrm{H}_{77} \mathrm{NO}_{10} \mathrm{P}$ & {$[\mathrm{M}-\mathrm{H}]-$} & $\mathrm{PS}(40: 6)$ & 0.96 \\
\hline 11 & 885.5505 & 885.5499 & $\mathrm{C}_{47} \mathrm{H}_{82} \mathrm{O}_{13} \mathrm{P}$ & {$[\mathrm{M}-\mathrm{H}]-$} & $\mathrm{PI}(38: 4)$ & 0.68 \\
\hline
\end{tabular}

SM: sphingomyelin, PC: Phosphatidylcholine, PE: Phosphatidylethanoamine, PI: Phosphatidylinositol TG: Triacylglycerol, PS: Phosphatidylserine, LPI: Lysophosphatidylinositol, Cer: Ceramide 